\title{
EUROPAEI, AUDI, QUID CONVENIT STATUITQUE DOMINA VERBUM!' \\ UNA MUESTRA (AÚN) RECIENTE DE LA ACTUAL JURISPRUDENCIA IUS EUROPEA DEL TRIBUNAL CONSTITUCIONAL FEDERAL DE ALEMANIA (TCFA) ${ }^{2}$
}

A still recent sample of the current ius European jurisprudence of the German Federal Constitutional Court (GFCC)

\author{
ANTONIO LÓPEZ CASTILLO \\ Universidad Autónoma de Madrid \\ antonio.lopez@uam.es
}

Cómo citar/Citation

López Castillo, A. (2017)

Europaei, audi, quid convenit statuitque domina verbum! Una muestra (aún) reciente de la actual jurisprudencia ius europea

del Tribunal Constitucional Federal de Alemania (TCFA). Revista Española de Derecho Constitucional, 111, 341-378. doi: https://doi.org/10.18042/cepc/redc.111.11

Resumen

La Sentencia OMT del TCFA supone un nuevo paso en la pretensión de reformular la relación de la LF y el DUE que caracteriza su reciente jurisprudencia ius

1 El presente trabajo se inserta en el marco del proyecto de investigación DER201678391-P («El control de la ley: constitucional, comunitario y convencional»), financiado por el MEIC.

2 Sentencia (OMT) del TCFA (Sala Segunda), de 21 de junio de 2016, as. ac. 2BvR 2728/13, 2BvR 2729/13, 2BvR 2730/13, 2BvR 2731/13, 2BvE 13/13. Entre los comentarios de interés, mencionaré uno en lengua alemana (Classen, 2016), y otros dos en lengua española (Sáinz de Vicuña, 2016; Toda Castán, 2017). 
europea. Si a finales de 2015 se ensayaba una comunicación indirecta con el TJUE, mediante una interpretación de conformidad sustentada en la incondicionalidad de los estándares integrantes de la identidad constitucional, en 2016 se ensaya una relación directa, en vía prejudicial. La firme predisposición del TJUE al diálogo, no obstante la singularidad procesal y sustantiva del caso OMT, se refleja en una «aclaración» que la Sala Segunda acoge de un modo equívoco y ambivalente, condicionando unos criterios cuya observancia se deja bajo vigilancia de los órganos constitucionales responsables por la integración. Todo apunta a que esta «disputa» continuará.

\section{Palabras clave}

Tribunal constitucional; Tribunal de Justicia de la UE; cuestión prejudicial; interpretación de conformidad constitucional; control de constitucionalidad; ultra vires; identidad constitucional; responsabilidad por la integración; derecho a la democracia; inaplicación del derecho de la UE.

\section{Abstract}

The OMT Judgment of the TCFA is a new step in the attempt to reformulate the relationship between the German Basic Law and the EU Law that characterizes his current European jurisprudence. If an indirect communication with the CJEU was attempted at the end of 2015, by means of interpretation of conformity based on the non conditionality of the standards that are part of the constitutional identity, in 2016 a direct relation is tried, in a preliminary way. The ECJ's strong predisposition to dialogue, despite the procedural and substantive uniqueness of the WTO case, is reflected in a "clarification" that the Chamber receives in an ambiguous and ambivalent manner, conditioning certain criteria whose observance is left under the supervision of the constitutional bodies responsible for integration. Everything points to this "dispute" will continue.

\section{Keywords}

Constitutional Court; Court of the European Union; preliminary ruling; interpretation of constitutional conformity; control of constitutionality; ultra vires; constitutional identity; responsibility for integration; right to Democracy; no application of the European law. 


\section{SUMARIO}

I. LA SENTENCIA OMT DEL TCFA: 1. Presentación en contexto. 2. Tenor. II. LAS FORMAS Y EL TRASFONDO EN LA «DISPUTADA» CUESTIÓN PREJUDICIAL OMT: 1. Consideraciones introductorias. 2. Singularidades procesales y trasfondo de la disputa (competencial/soberanista). III. LAS «DIRECTRICES» DOCTRINALES DE LA SENTENCIA OMT DEL TCFA: 1. Doctrinarismo autorreferencial que -verbo domini-, mediante una suerte de conceptismo culteranista, insufla un derecho mayúsculo y de proteico efecto. 2 . ...amparable mediante controles de ultra vires e identidad constitucional, en virtud de una responsabilidad por la integración... 3. ...que, en este caso, lleva a condicionar la participación del BuBa en una eventual puesta en marcha del programa OMT. IV. CONSIDERACIONES FINALES, A MODO DE CONCLUSIVA RECAPITULACIÓN. AdDENDA. Bibliografía.

\section{LA SENTENCIA OMT DEL TCFA}

\section{PRESENTACIÓN EN CONTEXTO}

1. En su esperada sentencia OMT, de 21 de junio de 2016, la Sala Segunda del TCFA ha tratado de dar respuesta a las pretensiones deducidas en una serie de procedimientos (acumulados y previamente «troceados»" interpuestos mediante concurrente iniciativa procesal de numerosos particulares (cuatro recursos de queja por inconstitucionalidad) y una minoría parlamentaria (conflicto de atribuciones).

En la decisión, que tiene su origen en la cuestión prejudicial planteada mediante Auto de 14 de enero de 2014 (su primera iniciativa de comunicación procesal directa con el TJUE ${ }^{4}$ ) y viene precedida de la respuesta que, año y

3 Según recuerda el propio TCFA (A. IV.1, párrafo 65), estos recursos fueron objeto de segregación temática, al efecto de resolver directamente sobre el fondo, por lo que respecta a buena parte de las cuestiones planteadas en esos recursos (cf. sentencia de 18 de marzo de 2014, en BVerfGE 135, 317 y sigs.), sin perjuicio del planteamiento, a propósito de otras cuestiones asimismo acumuladas, de una (duplicada) tanda de cuestiones, en vía prejudicial, ante el TJUE (según un tenor que literalmente se reproduce en IV. 2.), mediante Auto, de 14 de enero de 2014 (BVerfGE 134, 366, 369 y sigs.).

4 A propósito, véase López Castillo (2014: 315-325). 
medio más tarde, vino a dar el TJUE, mediante sentencia de su Gran Sala, de 16 de junio de $2015^{5}$, la Sala Segunda del TCFA se libra a una desenvuelta glosa de esa «jurisprudente» respuesta prejudicial $^{6}$, en un doble sentido que - si no se entiende mal - trasluce una intención de mantener expedito ese puente comunicativo como vía practicable para la prosecución del «disputado» intercambio de pareceres entre estas dos altas jurisdicciones.

La Sala celebra, de una parte, lo que considera un acierto. Que el TJUE haya visto en su auto una llamada al diálogo jurisdiccional, a pesar de que, en opinión extendida (sostenida tanto en los votos particulares discrepantes con el criterio mayoritario formulados por dos de los magistrados entonces aún integrantes de la Sala Segunda del TCFA, como por parte de algunos de los intervinientes en el proceso ${ }^{7}$ y, de modo preciso, también por parte del abogado general $(\mathrm{AG})$ — que, ello no obstante, recomendaría al TJUE un esfuerzo de contemporización y mesura para brindar una respuesta útil-), más parecía el anuncio, en vía prejudicial, de una alternativa hermenéutica al efecto de superar la oferta abierta sobre el anunciado programa OMT, como único modo de evitar (en el caso de que se llegase a poner en marcha) su inaplicación en Alemania.

Que el TJUE acoja su planteamiento (de cuestión ${ }^{8}$ ) prejudicial, por considerarlo «lícito y admisible», es algo que satisface a la Sala Segunda del TCFA. Por más que esa consideración («lícito») no deba entenderse ni como una convalidación de su admonitorio estilo, ni como una aceptación de la incondicionalidad de su cerrada oferta hermenéutica y de los anunciados efectos de su desatención (como bien se advierte en las críticas conclusiones del AG Cruz Villalón).

5 La sentencia, de 16 de junio de 2015, en la medida en que responde a las cuestiones planteadas mediante el Auto TCFA de 14 de enero de 2014, se entiende mejor si en su lectura se integran las críticas conclusiones que el AG Cruz Villalón presentara con fecha de 14 de enero de 2015.

6 Véanse, en detalle, núms. marginales 67, 68 y 69.

7 Véase párrafo núm. 68 de la sentencia TCFA, que, a propósito, remite a los párrafos 11-31 de la referida sentencia prejudicial de la Gran Sala del TJUE.

8 Por más que esta "cuestión prejudicial» acaso diste menos del añejo método escolástico (cual particular síntesis de sus modalidades: lectio, quaestio y disputatio) que de la canónica doctrina del TJUE a propósito de la función de los órganos cuestionantes, en esta específica vía de cooperación, al efecto de sentar la interpretación y de confirmar la validez del DUE (en todo caso, aquí el TJUE, enfatizando la "presunción de pertinencia», abstracción hecha de su mordiente doctrinal, en línea con la recomendación del AG, trata de brindar una respuesta útil, a los efectos del DUE, al TCFA. 
Satisface, asimismo, al TCFA que, contra el criterio manifiesto de algunos de los intervinientes en el procedimiento prejudicial, en línea con las conclusiones del AG, la Gran Sala considerase su auto como algo «admisible», entendiendo que no obstante su veste ${ }^{9}$, de la decisión OMT anunciada en rueda de prensa podrían derivar efectos que, al considerar una pretensión de tutela cautelar, un órgano jurisdiccional, como el cuestionante, estaría llamado a considerar, en el marco de procedimientos abiertos.

Se aconsejaba, así, la adopción de una respuesta prejudicial, útil al efecto de que el órgano jurisdiccional cuestionante, la Sala Segunda del TCFA, pudiese desempeñar su jurisdicción contando con la «aclaración» instada.

A esta respuesta prejudicial de la Gran Sala, que bien puede considerarse, mesurada, en cuanto al fondo, y componedora, en las formas, ha respondido la Sala Segunda del TCFA, de modo equívoco y ambivalente.

Pues, si bien, por un lado, persiste en la reafirmación de su propia jurisdicción de control de constitucionalidad de las actuaciones de los órganos constitucionales, integrando a su modo la que considera una respuesta parcialmente insatisfactoria (en atención, en particular, a la autocontención del TJUE a la hora de controlar la discrecionalidad decisoria de una institución técnica, de restricta legitimación democrática, como es el $\mathrm{BCE}$, cuando lo indicado habría sido la práctica de un control jurisdiccional más estricto e intenso ${ }^{10}$ ).

Por otro lado, en atención al parcial acogimiento de su crítico planteamiento prejudicial, con base en un razonamiento relativo al principio de proporcionalidad (presente en las conclusiones del AG, como criterio paramétrico de la aplicación del anunciado programa $\mathrm{OMT}^{11}$ ), cohonestable con sus referencias a la responsabilidad por la integración de los órganos constitucionales (de cuya observancia le cumple ocuparse mediante controles de ultra vires o/e

9 A propósito, sin necesidad de un mayor detalle jurisprudencial y doctrinal, puede mencionarse, en esa misma línea de flexibilización, la sentencia del TG, Sala Cuarta, de 4 de marzo de 2015, as. T-496/11, Reino Unido/BCE, donde el objeto de consideración ha sido un «informe» (marco de vigilancia del Eurosistema) publicado por el BCE, el 5 de julio de 2011 (núm. marginal 54: «[...] debe deducirse del análisis de su tenor literal y del contexto en el que se inscribe, de su contenido esencial así como de la intención de su autor, que el marco de vigilancia produce efectos jurídicos y constituye, por ello, un acto susceptible de recurso de anulación [...]), finalmente, anulado, «en la medida en que establec[ía] una exigencia de domiciliación dentro de un Estado miembro de la zona euro a las entidades de contrapartida central que intervienen en la compensación de valores financieros» (fallo, 1.).

10 Véanse, en detalle, núms. marginales 182,183 y sigs. y 187 y sigs.

11 A propósito, véanse párrafos núm. 171 y sigs., 177 y sigs. y 185 y sigs. 
identidad constitucional $)^{12}$, estima la Sala Segunda que la «aclaración» prejudicial de la Gran Sala aún no desbordaría el mandato jurisdiccional que, ex art. 19. 1 y 2 TUE, se atribuye al TJUE. Y, al margen de insuficiencias, el TCFA acuerda desestimar todas las pretensiones admitidas.

Lo ambivalente está en que ni la inadmisibilidad de las unas, ni la desestimación de las otras, acaba con planteamientos críticos que, en la medida en que no se modulan, mediante condicionamiento interpretativo de la participación del BCE en la eventual aplicación del programa OMT (véase directriz número 4) sujeta a vigilancia del Gobierno y de la Dieta federal, parecieran diferirse a una segunda ronda prejudicial.

Lo equívoco está en la proyección de esa doctrina en el caso, dado que en el momento de dictarse sentencia era sobradamente conocido por el TCFA que, ya desde el inicio de 2015, el BCE venía adoptando otras iniciativas, dejando inactivado el programa OMT. Pero si se ha de conceder a la Sala el beneficio de la duda, quizás pueda pensarse que, al proceder así, hubiese pretendido adelantar unos criterios operativos para dejar abierta la búsqueda de una salida practicable, al abordar la resolución de otros recursos pendientes, relativos a programas en aplicación.

2. A propósito del contexto, antes de volver sobre esos otros procedimientos pendientes hay que destacar una decisión de alcance acerca del control de identidad constitucional, adoptada, a caballo de sus resoluciones (auto prejudicial y sentencia) OMT, mediante Sentencia de 15 de diciembre de 2015, en la medida que abre un alternativo cauce de «diálogo» con el TJUE. Sin las ataduras procesales que resultan de la institucionalizada cuestión prejudicial; conforme a sus propias reglas.

Desechando la activación de esa vía de comunicación directa, para sí y para el órgano jurisdiccional, cuya resolución se cuestionaba en recurso de queja por inconstitucionalidad, se impuso allí una interpretación constitucionalmente conforme de la normativa nacional, orillando el marco ius europeo, pese a su incidencia en el caso ${ }^{13}$.

Sobre las dudas que a propósito de su interlocución prejudicial con el TJUE ese proceder pudo dejar, ocasión habrá de volver al considerar la

12 A propósito véanse, en detalle, núms. marginales 190, 193 y sigs., 197 y sigs., 200 y 205 y sigs.

13 A propósito de esta sentencia, por la que se ordenaría, en queja por inconstitucionalidad, amparar a un extranjero condenado en ausencia en otro país miembro de la Unión, se remite aquí, por otros, a López Castillo (2017: 387-412); Arzoz Santisteban (2016: 1-40). 
pendiente resolución de recursos de queja por inconstitucionalidad ${ }^{14}$ relativos al programa de compra de activos financieros emitidos por las administraciones centrales y por entidades públicas de los Estados de la eurozona o Public Sector Purchase Programme (PSPP), que, como modalidad del programa marco de compra de valores, Expanded Asset Purchase Programme (EAPP), habría permitido al BCE poner en el mercado, al efecto de superar posibles derivas deflacionarias en la eurozona, un montante mil millonario que, mediado ya el año en curso, pasaba del $80 \%$ del total de las compras realizadas en el marco del programa EAPP ${ }^{15}$.

14 Dirigidos contra las decisiones del Consejo Ejecutivo del BCE relativas a la concreción (PSPP, ABSPP, CBPP) del llamado programa ampliado de compra de activos o EAPP, así como contra las actuaciones que a propósito se adoptaran o no por parte de la Dieta, del Consejo y del Gobierno federales, a instancia tanto de viejos conocidos, como de nuevos «querulantes soberanistas», promotores todos de la hipertrofiada jurisdicción de control de la responsabilidad por la integración por parte del TCFA.

En total, los recurrentes suman tres (2 BvR 859/15), cinco $-+1729-(2 \mathrm{BvR}$ 1651/15), uno (2 BvR 2006/15), —dos (2 BvR 43/16) - y nueve (2 BvR 980/16), respectivamente (véase $A d d e n d a)$.

Por lo demás, de entre los asuntos pendientes de ese ponente (Peter M. Huber) cabría referir otras quejas por inconstitucionalidad (en relación con el llamado mecanismo simple de supervisión [SSM], mecanismo único de supervisión bancaria y ley de asentimiento y otros actos de derecho derivado — 2 BvR 1685/14_, o, ya en otro plano - de específico antecedente en la vieja jurisprudencia Eurocontrol I y II-, en relación con una denuncia de insuficiente prestación de tutela judicial efectiva, supuestamente vulneradora de los art.s 2.1, 19.4, 20.3, 24.1 y 103.1, todos de la LF, por parte de la Sala de Recursos de la Oficina Europea de Patentes — 2 BvR 2480/10, 2 BvR 421/13, 2 BvR 756/16, 2 BvR 786/16-).

15 Ello responde a una decidida política de intervención monetaria, adoptada al amparo, entre otras disposiciones, del art. 18.1 Estatuto SEBC (disposición asimismo invocada a propósito del inactivado programa), sujeta a crítica, particularmente, en el espacio político/jurisdiccional alemán.

Lejos de darse por concluso, el programa de compra de valores públicos en los mercados secundarios se habría prorrogado, si bien rebajando a 60000 millones de euros el montante mensual de la intervención, hasta finales de 2017, «o más allá si fuera necesario", si, como consecuencia de discrecional valoración acerca del grado de consecución de los objetivos establecidos, así se decidiese (véase la Decisión 2015/774, modificada por la Decisión —UE_, 2017/100 BCE, de 11 de enero).

Con todo, el reciente anuncio de gradual ajuste de las medidas extraordinarias a fin de acompasar las políticas del BCE a la recuperación de la eurozona (eso que en la jerga bancaria al uso se denomina «intervención verbal») aconseja esperar al inicio del curso, antes de aventurar nada sobre la suspensión o la continuación, modificando o no el 
Para la cabal comprensión de la adopción de medidas no convencionales por el BCE, cabe recordar que el programa OMT, concebido como alternativa al programa del mercado de valores (SMP), quedaría superado en la práctica ya desde enero de 2015.

Por lo demás, la referencia al programa SMP tiene un añadido interés procesal. Pues sin una previa constatación de inoperancia de la «resistencia» al interno del $\mathrm{BCE}^{16}$ quizás no se hubiese asistido a la inusitada aceleración procesal de la reacción (soberanista), en tropel de recurrentes que, en su papel de querulantes soberanistas, no dejarían pasar una semana desde el anuncio del programa OMT para acudir al TCFA.

\section{TENOR}

En lo ambivalente y equívoco de su discurso, el tenor de las directrices de la sentencia OMT denota cierta falta de candor.

Pues al tiempo que declara la inadmisibilidad de las pretensiones directamente deducidas contra las actuaciones del $\mathrm{BCE}^{17} \mathrm{y}$ desestima las pretensiones admitidas a trámite, conforme a unos condicionamientos a los que expresamente se remite el fallo al efecto de integrar su sentido y alcance ${ }^{18}$, la sala persiste en su línea (entre conceptista y mañosa) de reinterpretación de la "cláusula Europa», en esa deriva unilateralista (entre ius internacional y confederal), característica de su jurisprudencia ius europea de "entre siglos», mediante reafirmación de su reserva de jurisdicción de control (en la doble vía de ultra vires e identidad constitucional) de la responsabilidad por la integración de los órganos constitucionales, a instancia de los ciudadanos.

Con ello, no se trataría tanto de reafirmar una supremacía de la Constitución que, en lo sustancial, no estaría en discusión como de ampliar su perímetro de intangibilidad, mediante un utillaje conceptual que, caso mediante, ayuda a configurar su alternativa concepción de la interrelación del derecho nacional (alemán) con el DUE.

programa, de la política de compras (a propósito, véase «Mario Draghi avanza que habrá un ajuste gradual de la política del BCE» en El País, fecha: 27 de junio de 2017).

16 Esa resistencia intestina se tradujo en la sucesiva espantada, como miembros del Comité Ejecutivo, de Axel Weber, sucesor in pectore entonces de Trichet, al frente del BCE, y de Jürgen Starck, presidente y exvicepresidente del BuBa, a lo largo de 2011 (véase Sáinz de Vicuña, 2016: 1072).

17 Véase, en detalle, en C. II. y C. III. 2.

18 Véase, en detalle, en D. II. 3. 
De eso, solo en parte, descartada una sinderética lectura de tópicos, dan cuenta las «directrices» que, en su frontispicio, decantan su doctrina y la precisan en el caso.

Por ello, para poder valorar en su justa medida esa referida falta de candor, nada más indicado, por su objetiva literalidad, que su íntegra reproducción aquí ${ }^{19}$ :

1. A fin de asegurar sus posibilidades de influencia democrática en el proceso de integración europea, el ciudadano tiene por principio un Derecho a que una «transferencia de derechos de soberanía» se produzca solo en las formas al efecto previstas en los artículos 23.1, segunda y tercera frases, y 79.2, LF.

2. (Las) medidas (de los) órganos, organismos y demás autoridades de la Unión Europea (UE) que incurran en ultra vires vulnerarán el programa de integración formulado, conforme al artículo 23.1, 2. a frase, LF, en la ley de autorización y con ello, al mismo tiempo, el principio de la soberanía popular (artículo $20.2,1 .^{a}$ frase, LF). A la evitación de tales vulneraciones jurídicas sirve el instituto del control de ultra vires.

3. A los órganos constitucionales les cumplirá, en virtud de la responsabilidad por la integración que les incumbe, la obligación de actuar frente a (las) medidas (de los) órganos, organismos y demás autoridades de la Unión Europea (UE) que provoquen una lesión de la Identidad o representen un acto Ultra vires. 4. El Banco federal alemán solo debiera participar en una futura realización del programa-OMT cuando, y en la medida en que, se cumplan los criterios sentados por el TJUE, es decir solo si:

- previamente se limita el volumen de compra,

- entre la emisión de los títulos de deuda y su compra por el SEBC media un plazo mínimo previamente establecido que impida que se falseen las condiciones de emisión,

- se adquieren títulos de deuda de Estados miembros que solo tengan (por efecto) posibilitar su acceso a financiación en los mercados de empréstito,

— los títulos de deuda, solo excepcionalmente, se mantienen hasta su plazo de vencimiento, y

— se limitan o suspenden las compras y los títulos adquiridos se devuelven al mercado tan pronto como no sea ya necesario proseguir con la intervención.

Pero antes de proceder a la sintética glosa de ese denso precipitado doctrinal (III.), alguna consideración o apunte se habría de hacer a propósito de la conjunción

19 En versión propia, no oficial. 
de lo procesal y lo sustantivo en la parabólica trayectoria de semicircularidad que va del Auto a la Sentencia OMT (II.). Y, a modo de conclusiva recapitulación, en síntesis, se ha de glosar lo auto referencial del discurso que marca el acelerado tempo del "giro interpretativo ${ }^{20}$ que, en su jurisprudencia ius europea más reciente, mediante torsión y retorsión funcional, singulariza ya la presidencia Vosskuhle del TCFA (IV.). Por último, se incluye la referencia bibliográfica de los trabajos citados en estas páginas.

\section{LAS FORMAS Y EL TRASFONDO EN LA «DISPUTADA» CUESTIÓN PREJUDICIAL OMT}

\section{CONSIDERACIONES INTRODUCTORIAS}

Para dar cuenta de la «escaramuza» prejudicial, reconducida (bajando la intensidad crítica que late en algunos pasajes de las conclusiones del AG Cruz Villalón, de 14 de enero de 2015) mediante sentencia de la Gran Sala del Tribunal de Justicia de la Unión Europea (TJUE), de 16 de junio de 2015, bien puede emplearse aquí la figurada imagen de un arco de parabólica traza semicircular, que va del Auto prejudicial, de 14 de enero de 2014, a la Sentencia OMT, de 16 de junio de 2016, de la Sala Segunda del TCFA. Pues, como otros posibles símiles ${ }^{21}$, denota tanto lo que haya podido pasar $\left(1 .^{\circ}\right)$ como lo que aún falta por llegar (2..$^{\circ}$, antes de que el TCFA pueda pensar en culminar esa especie de ensayo de cuadratura del círculo, que late en su oferta de alternativa concordancia de planteamientos «lógicamente» incongruentes.

1. Si bien se mira, con el sobreactuado lanzamiento de su (primera) iniciativa prejudicial, el TCFA habría venido a plantear al TJUE la posible

20 Tomo la expresión, como paráfrasis de «giro argumentativo» (Atienza Rodríguez, 2014).

21 Así, por ejemplo, si en un ejercicio de ficción se diera con el registro de una hipotética comunicación por radio, bien podría escucharse: 1.․ TCFA (¡Aquí Karlsruhe: A ver que respondéis... porque si decís lo que no queremos escuchar, es muy posible que no se os vuelva a preguntar... y tened por seguro que, en todo caso, se procederá según nuestro propio criterio... cambio!); 2.․ TJUE (¡Aquí Luxemburgo: no vamos a darnos por aludidos y, por no incurrir en grosera desconsideración, ahí va la respuesta que se nos inquiere... y que bien haríais en seguir... cambio y cierro!); y 3. ${ }^{\circ}$. TCFA (¡Aquí... — se oyen interferencias—, sí, ya, pero sabed que... no puede quedar así... (¡y se interrumpe la comunicación!). 
sustitución de unos criterios técnicos (los sostenidos por el BCE) por otros (los defendidos por el Banco Federal Alemán, $\mathrm{BuBa}$ ), cuestionando el anclaje en el derecho primario de la Decisión OMT. Al efecto, la Sala Segunda habría puesto al TJUE ante la alternativa tesitura de: o bien asumir su planteamiento acerca de que el anuncio del programa OMT supondría un exceso competencial del BCE carente de sustento en el derecho primario, tanto por insuficiencia de base jurídica y desproporción de su previsible actuación como por el desconocimiento de la interdicción iuseuropea de financiamiento del sector público, o bien exponerse a la posible quiebra en Alemania de la «expectativa de primacía de aplicación del DUE», previa declaración de su ineficacia en el caso.

Al plantearse así la cuestión, se estaba haciendo algo más que "preguntar» (como bien se advirtiera ya en los votos particulares de Gerhardt y de Lübbe-Wolf), se estaba tensando el rendimiento cooperativo del cauce procesal de comunicación prejudicial con el TJUE (como bien subrayaran las conclusiones del AG Cruz Villalón y las intervenciones de algunos Estados miembros), tanto por la altisonancia del desafío como por su trasfondo de marcada torsión y retorsión funcional.

«Torsión», por lo que tiene de extensiva (¿por qué no legiferante?) lectura del derecho procesal constitucional que disciplina su actuación (a propósito, en particular, de su flexibilización, hasta la estricción de su ley procesal, del régimen de legitimación de los recurrentes y de su posible -inmediato/ mediato- objeto del control). Y «retorsión» porque de su alternativa "oferta interpretativa» resulta un corolario que expone a alta tensión la constitutiva divisoria jurisdiccional entre TJUE y TCFA.

2. Lo que aún esté por llegar depende de cómo y cuándo se reanuden las «escaramuzas». La pendiente resolución de recursos de queja por inconstitucionalidad acumulados, a propósito del programa de compras conocido por sus siglas PSPP, bien puede brindar una segunda oportunidad que la Sala parece aguardar para proseguir en (la escalada o el enfriamiento) de su desafío prejudicial.

Si con ello se cerraría o no el círculo, si se animaría o no la Sala a ensayar su (gaussiana) «cuadratura»" ${ }^{22}$ es cosa de dos; del TCFA y, así como de otros partícipes que pudieran venir a terciar en el debate ${ }^{23}$, sin duda alguna, también del TJUE.

22 A propósito de la controversia geométrica en relación con la "cuadratura del círculo» (es decir, con la obtención de una misma área pasando de una a otra figura geométrica) se remite aquí, a simple título ilustrativo, a la contribución de Bombal Gordon (2012: 241-258).

23 A propósito, véase, por otros, Aragón Reyes (2009: 345-368). 


\section{SINGULARIDADES PROCESALES Y TRASFONDO DE LA DISPUTA (COMPETENCIAL/SOBERANISTA)}

Entre las singularidades procesales de la sentencia OMT (2.1.) se tratará aquí, por una parte, de la superación procesal de la situación creada por la alteración de la composición personal de la Sala Segunda en el tracto que va del auto a la sentencia OMT, y, por otra parte, de los sujetos legitimados y del objeto propio (e impropio) de las pretensiones deducidas. Y, en lo demás (2.2.), se tratará de la complementaria confluencia de los controles de ultra vires e identidad constitucional, como instrumento de control de la obligación constitucional por la integración que, como objetivo reflejo del «derecho a la democracia» del ciudadano, concierne a todo órgano constitucional.

2.1. En este plano procesal se tratará de una cuestión orgánico-funcional $\left(1 .^{\circ}\right)$ antes de poner el acento en la interpretación del título de legitimación y el objeto de control (2.\%).

1. Lo primero a señalar es la alteración de la composición personal de la Sala Segunda que media entre el planteamiento del auto y la adopción de su Sentencia OMT, por la salida de dos de sus integrantes, los magistrados Gertrude Lübbe-Wolf y Michael Gerhardt ${ }^{24}$, discrepantes con el criterio mayoritario sustentado en el Auto OMT ${ }^{25}$.

Esa renovación personal de la Sala sería vista como una ocasión pintiparada para recomponer la unidad interna del colegio, sumando así a nuevos integrantes (König y Maidowski) ${ }^{26}$, que no habrían concurrido a la adopción

24 La jueza Lübbe-Wolf sería sustituida, cumplido su mandato, por la colega Doris König (véase la nota de prensa del TCFA, núm. 47/2014, de 30 de mayo). Michael Gerhardt, un «espíritu independiente» (véase, a propósito de esto, «Wechsel in Karlsruhe. Ein Verfassungsrichter will gehen», noticia firmada por Stefan Geiger, con fecha 5 de mayo de 2014, reproducida en Stuttgarter-Zeitung.de), dejaría prematuramente el TCFA, tras inesperado anuncio previo, unos meses antes, siendo sustituido por Ulrich Maidowski (véase la nota de prensa del TCFA, núm. 59/2014).

25 En su crítica opinión adujeron razones jurídicas y de política (jurisprudencial) constitucional, en una línea que hace parte de la tradición institucional del TCFA. Véase Jestaedt et al. (2011); Shu-Pern Hwang (2015: 179-206).

26 Más reciente aún es la última incorporación a esa Sala de Christine Langenfeld, reclutada entre las seis juristas que se postularon al efecto, en sustitución del («muy conservador») Herbert Landau, con fecha 20 de julio de 2016 (véase la nota de prensa del TCFA, núm. 44/2016, de 19 de julio). 
de su decisión prejudicial mediante Auto de 14 de enero de 2014 ni habrían sido partícipes tampoco de la actividad procesal previa (audiencia pública, de 11 y 12 de junio de 2013; adopción de la decisión de desagregar en dos los procedimientos acumulados, con fecha de 17 de diciembre de 2013.

La Sala negaría la aplicación en el caso de la regla de exclusión de participación de los jueces en asuntos deliberados o en proceso de deliberación, ex art. 15.3, primera frase, de su ley procesal, por haber mediado una intervención externa, la intervención prejudicial del TJUE. Y, en atención a esa intervención prejudicial del TJUE y al tiempo transcurrido desde la primera deliberación, acordaría nueva deliberación colegial ${ }^{27}$, brindando así a los intervinientes la ocasión de profundizar en sus planteamientos críticos acerca del programa OMT y de su eventual ejecución ${ }^{28}$.

2. En segundo lugar, recompuesto ya el criterio colegial, la Sala prosigue en su línea de extensiva interpretación del título de legitimación, en queja por inconstitucionalidad y en conflicto de atribuciones, y de su objeto posible de control, en las modalidades de ultra vires e identidad constitucional.

A propósito de los sujetos legitimados, se recordará que, con ocasión del auto prejudicial, al interno de la Sala se había criticado el derrotero hacia una singular especie de actio popularis, legalmente imprevista ${ }^{29}$. Superada esa discrepancia interna, la Sala persiste en una tesitura instrumental tendente a garantizarse unos cauces al efecto de examinar la conformidad constitucional

27 Según se expone en el apartado B (I, II y III) de la sentencia, esta decisión, previa determinación de que no tomasen parte en la misma los dos nuevos miembros integrantes de la Sala Segunda, pudo ser adoptada, con fecha 3 de junio de 2015, por amplia mayoría de cinco votos contra uno.

28 Véase núm. marginal 70, en A. IV. 4. A propósito de esta nueva ronda de intervenciones, se ha criticado el contraste procesal de la intervención del presidente del Banco federal ( $\mathrm{BuBa})$, en defensa de su posición institucional y atribuciones, frente a la participación, en calidad de perito, de un miembro del directorio del BCE, de nacionalidad alemana (en esa deficiente articulación procesal de la voz del BCE en esos procedimientos acumulados ha insistido, en particular, Sáinz de Vicuña [2016: 1075], por considerarla expresión de una insatisfactoria observancia de las exigencias del debido proceso; garantía integrante, según la STCFA de 15 de diciembre de 2015, de la incondicionada cláusula de identidad constitucional, ex art. 1.1, en relación con el art. 79.3, todos de la LF, que, como bien es sabido, encuentra su expresa formulación en el artículo de la Carta de DDFF/UE).

29 Véase VP de Lübbe-Wolf. En esa línea, véase, por otros, Wendel (2014); López Castillo (2014). 
de actuaciones omisivas que, de otro modo, difícilmente podrían verse expuestas a su control.

Sin el empeño pretoriano de anudarlo, cual subjetivo reflejo de un objetivo principio estructural, como el principio democrático, ese Derecho, con mayúscula y de proteico alcance, no pasaría de ser una mera expectativa política ciudadana de pretendida salvaguarda de la suficiencia soberana de la democracia en Alemania.

En cuanto a la vía del conflicto, un procedimiento constitucional de disputa, por sus respectivas atribuciones, entre órganos constitucionales, en cuyo marco cabe la invocación de sus derechos constitucionales (y, por extensión, reglamentarios) por parte de minorías parlamentarias; también al efecto de salvaguardar las atribuciones de su respectivo órgano constitucional.

Ahora bien, en el presente caso, la parte recurrente, un grupo parlamentario de la Dieta federal, denominado "La izquierda», habría dirigido su alegato no contra otro órgano constitucional en defensa de las atribuciones de la Dieta federal, sino frente a su propia Cámara ${ }^{30}$. Cuestionando una práctica política que se considera lesiva tanto de su estatuto constitucional (algo sin lo que los parlamentarios y las fracciones parlamentarias apenas podrían rendir el ejercicio de su función crítica frente a las mayorías parlamentarias de gobierno; algo que, en el caso español, en buena medida se canaliza por la vía del amparo) como de las propias atribuciones del BTag, con manifiesta merma de representatividad del pueblo (nacional) soberano.

Así pues, lo que el grupo parlamentario pretende en este caso del TCFA no es tanto salvaguardar sus derechos como grupo parlamentario como que, contrariando el discrecional criterio de la Cámara, se intervenga al efecto de asegurar la remanencia de las atribuciones, legislativas y presupuestarias, que le confieren su centralidad política.

Al plantearse así la denuncia, frente a una supuesta falta de reacción, por no decir dejación de atribuciones, de potencial efecto irreversible (por supuesta admisión de un proceso de «usurpación» de la soberanía nacional), se habría perdido de vista que lo realmente cuestionado aquí no es una actuación subversiva del BTag, adoptada al margen de las previsiones constitucionales ${ }^{31}$, sino una

30 A propósito del BTag como contraparte procesal de sus miembros y grupos integrantes y a la actuación omisiva como objeto posible de conflicto de atribuciones ya se había pronunciado la jurisprudencia del TCFA (E 121, 135, 150; E 139, 194, 220; véase núm. marginal 110-2, en C. III. b).

31 Esa caracterización, operativa en relación con supuestos auténticos de usurpación, extramuros del orden constitucional, sin excluir que, por hipótesis, pudiera ello 
decisión política deferente con los compromisos que, en un confluente marco de atribución de responsabilidades a la UE, se hayan podido asumir.

$\mathrm{Y}$ esa misma expectativa iusfundamentalizada es la fuente de legitimación de los particulares en la vía del recurso de queja por inconstitucionalidad. En virtud de una configuración del derecho ius fundamentale simile a la democracia nacional concebida como faceta subjetiva, invocable ante el TCFA, en defensa de un principio democrático, limitable, pero no de modo incondicionado, que, como elemento integrante de la identidad constitucional, delimita el alcance de lo transferible, tanto en el momento de configuración del DUE, como a la hora de su aplicación ${ }^{32}$.

En cuanto al «objeto» de control en sendos recursos de queja por inconstitucionalidad y conflicto de atribuciones, la Sala actúa de modo diferenciado ${ }^{33}$.

plantearse en relación con actuaciones relativas al cumplimiento de obligaciones de pertenencia a la UE, en el caso, resulta desproporcionada.

En un escorzo comparatista, una denuncia semejante de usurpación tiene sentido, si se plantea en relación con las minorías parlamentarias en el seno de la Cámara autonómica de la Comunidad Autónoma de Cataluña, cuando la mayoría acuerda privar de su participación, o lamina sus posibilidades de intervención, en debates que pretenden adoptar decisiones, acuerdos, resoluciones y disposiciones normativas que, al margen de su desconocimiento de la normativa reglamentaria, tienen una clara, o velada, finalidad de «usurpación» del fondo competencial atribuido a los órganos constitucionales representativos del pueblo soberano (véase STC 90/2017, de 5 de julio; véase, a propósito de otras referencias previas, TC, nota informativa núm. 9/2017, de 16 de febrero, y, como manifestación última, STC 114/2017, de 17 de octubre).

32 Por más que la gradual superación de los espacios nacionales cerrados, no obste per se que se avance en la legitimación democrática del poder en un marco de supranacionalidad, cual es el incipiente caso de la UE, ni de exigencias éticas de autonomía personal, a la kantiana, resulte tampoco obstáculo insuperable alguno. Pues bien, por más que aquí no se trate del establecimiento de artefacto o constructo imperial alguno, sino de una apertura constitucional que, en el contexto envolvente de la globalización, rehuyendo la tentación de tornaviaje al Estado comercial cerrado ( $E l$ Estado comercial cerrado (1991) [Der geschlossene Handelsstaat, 1800] se titula la conocida obra de Johann Gottlieb Fichte), persigue la imbricación de sus Estados miembros, en concordancia con el kantiano horizonte de confluencia republicana, como instrumento político indicado al efecto de una mejor garantía de salvaguarda de la paz perpetua (Immanuel Kant, Sobre la paz perpetua (2016) [Zum ewigen Friden, 1795]), la Sala insiste en su empeño de relectura del fundamento constitucional de su integración.

33 A propósito de las respectivas pretensiones no admitidas a trámite, en los recursos de queja por inconstitucionalidad y en el conflicto orgánico de atribuciones, véase, en detalle, C. II., 95-104 y 113. 
La Sala diferencia, de una parte, entre las quejas elevadas contra las actuaciones del $\mathrm{BCE}$ y las pretensiones deducidas contra las actuaciones, por omisión, ya fuese del Gobierno federal, o de la Dieta federal; y traza, de otra parte, una línea divisoria entre aquellas tachas en las que se denunciaba la inactividad, bien del Gobierno federal, bien de la Dieta federal, al efecto de impugnar o anular la decisión OMT, y aquellos otros pedimentos que pretendían el condicionamiento de decisiones del Gobierno o/y de la Dieta federal relativas a la asunción de responsabilidades y riesgos financieros.

Se da, así, diversa respuesta a las pretensiones deducidas frente a la decisión adoptada por el BCE y a las denuncias por inacción de los órganos constitucionales.

La Sala insiste en que solo las actuaciones de los órganos nacionales podrían ser objeto directo de control mediante recurso de queja por inconstitucionalidad, declarando inadmisibles las quejas dirigidas contra la anunciada decisión OMT del BCE.

A mediados ya de 2016 se confirma que, en su función de garantía de los (principios y) derechos fundamentales, de incondicionada aplicación, solo procedería a controlar actuaciones de los órganos constitucionales y demás autoridades públicas que, por acción o por omisión, pudieran desconocer su responsabilidad por la integración ${ }^{34}$.

34 Véase, a propósito, núms. marginales 98 y 99. En este punto, no estará de más recordar que, a propósito del objeto posible de control, el TCFA ha venido oscilando entre su marcada divisoria inicial (decisiones de los sesenta) y la afloración de una reserva jurisdiccional de control indirecto (véase Solange I, 1974); entre la negativa de jurisdicción complementaria o subsidiaria alguna de control jurisdiccional de las actuaciones de organismos supranacionales (véase Eurocontrol I, 1981, y II, 1982) y su extensiva consideración como objeto posible de control de aplicación en observancia del irrenunciable parámetro constitucional (véase Maastricht, 1993); y de la formalización de la reserva «en tanto que» (véase Solange II, 1986; Plátanos, 2000) a la paulatina modulación de la presupuesta divisoria funcional de las jurisdicciones nacional y comunitaria, configurando, primero, una modalidad de control constitucional (de último recurso, previo planteamiento de cuestión prejudicial al TJUE) sobre la aplicación del DUE en supuestos de actuación de la Unión ultra vires de sus atribuciones (véase Kloppenburg, 1987; Honeywell, 2010) y, segundo, mediante una comprensiva modalidad de control (indirecto) de la aplicación del DUE, al hilo de un control directo de las actuaciones, por acción u omisión, de los órganos constitucionales nacionales al efecto de salvaguardar la «identidad constitucional» que, en el ejercicio de su respectiva responsabilidad por la integración, a todas obliga y de cuya observancia se encarga, en último término, el propio TCFA (Lisboa, 2009), sentando los estándares constitucionales que, integrando la referida cláusula de identidad 
Ahora bien, con ser cierto que teóricamente ello redunda en la salvaguarda de la divisoria presupuesta entre sendos ordenamientos en el marco de la integración y, por tanto, también, en la divisoria jurisdiccional entre el TJUE y el TCFA, en la (in)cierta medida en que los efectos derivados de tales controles de constitucionalidad pudieran incidir en la expectativa de preferente aplicación de las actuaciones imputables a la UE, esa divisoria podría quedar en entredicho. Aun si viniese ello precedido, por considerarse preciso ("en lo posible»), del planteamiento de una cuestión prejudicial.

Lo que, lejos de asegurar la divisoria, condicionaría su observancia a la decisión (primera $-\mathrm{o}$ última - , según prescindiese $-\mathrm{O}$ no— de la cuestión prejudicial) del TCFA.

En sentido formal, no obstante, solo las actuaciones que, por acción u omisión, se imputaran a los órganos constitucionales serían objeto directo de su control.

En el caso, la Sala brinda un diferente trato procesal a las quejas, según que pusieran, o no, de manifiesto que la inacción denunciada pudiera suponer un quebranto de la responsabilidad por la integración, bien del Gobierno, bien de la Dieta federal.

Y por estimarse insuficientemente acreditadas, es por lo que se declaran aquí inadmisibles las pretensiones relativas a la imprevisión de condicionamientos y falta de información acerca del volumen y los plazos de duración del programa ${ }^{35}$.

Admitidas serían, en cambio, las quejas que denunciaban la inacción del Gobierno y de la Dieta federal por no haber impugnado el programa OMT ante el TJUE, ni haber intentado tampoco su anulación, por exceso competencial (del BCE), contrario a la divisoria entre política monetaria y política económica y lesivo de la palmaria interdicción convencional de financiamiento estatal directo.

Presumiendo esa deriva del rumbo preestablecido, y descartada la pretendida vía de control directo del anunciado programa OMT, la Sala profundiza en su planteamiento relativo al control directo de la responsabilidad

constitucional, resultarían de obligada aplicación en el espacio nacional alemán, en su caso, sin previo planteamiento de cuestión prejudicial (STCFA, 15.12.2015).

35 Al Gobierno federal se le reprochaba, en recurso de queja por inconstitucionalidad, no haber procurado asegurar el límite de la responsabilidad financiera de Alemania, de modo que no fuese a superar lo dispuesto ex art. 8.5 del tratado constitutivo del MEDE; y a la Dieta federal se le imputaba otro tanto, en el marco del conflicto de atribuciones, así como no haberse informado lo suficiente en cuanto al volumen y duración de la compra anunciada (en esto, tanto en una como en otra vía procesal). 
por la integración de los órganos constitucionales sustentados en la mayoría política, en su veste gubernamental o como encarnación de voluntad expresa o implícita - de la Dieta federal. En el caso, si bien no se advierte ese incumplimiento, la Sala, mediante desglose de la genérica obligación constitucional, prescribe a Gobierno y Dieta federal una complementaria obligación de vigilancia de las actuaciones del BCE, de llegarse a aplicar el programa OMT.

La parcial inadmisión y la desestimación, en lo demás, de los pedimentos no debiera confundir, pues, acerca del proceder de la Sala, que, al tiempo que se faja en el intercambio, avanza en su propósito de relectura de la "cláusula Europa» y decantación pretoriana de las modalidades de control, de ultra vires y de identidad constitucional.

2.2. A propósito del trasfondo de esta disputa (competencial/soberanista) conviene precisar que, en su sostenida crítica de un programa (OMT) que incidiría en materia económica (fiscal, social, etc.) tanto como en la propia política monetaria, la Sala aduce junto a razones jurídicas, discutibles pero sostenibles (así, por ejemplo, al advertir acerca de la interdicción de acceso al mercado primario de la deuda, o cuando, a contrario, se invoca la STJUE Pringle a propósito de las intervenciones del MEDE) ${ }^{36}$, otros criterios expresivos de un voluntarioso seguidismo de las tesis del $\mathrm{BuBa}$ (así cuando se pretende que el TJUE haga suya la exigencia de que el BCE se asegurase la posición de acreedor preferente o se insiste en que una intervención selectiva en el mercado secundario de deuda pública resultaría contraria al $\mathrm{DUE}^{37}$ ).

En lo que tiene de «alegato de parte», el discurso hilado por la Sala Segunda del TCFA trasluce una intención, si no de formular juicios políticos,

36 Acerca de la dimensión monetaria y económica de la intervención del MEDE en el mercado de deuda pública, por contraste con la banca central, véase la sentencia plenaria del TJUE, de 27 de noviembre de 2012, Th. Pringle/Irlanda, as. C-370/12 (véanse las conclusiones de la AG Kokott, de 26 de octubre de 2012).

37 Entiende la Sala que una selectiva intervención en el mercado secundario de la deuda, como la anunciada, en su pretensión de salvaguardar la estabilidad monetaria de la eurozona y la viabilidad misma del euro, pondría en riesgo la viabilidad misma de la propia eurozona, en tanto que «comunidad de estabilidad», desbordando el "programa de integración» democráticamente legitimado e incurriendo en ultra vires afectando, por extensión o conexidad, la cláusula de identidad constitucional. Véase, desde una perspectiva doctrinal próxima a la del BCE, la rotunda crítica de una pretensión que se considera contraria a los usos del mercado: Sáinz de Vicuña (2016: 1081). 
sí de sostener un alternativo criterio de discrecional, defendido, no obstante su desestimación al interno del BCE, por el Banco federal de Alemania.

La invocación de los controles de ultra vires e identidad constitucional no oculta, pues, lo inconsistente de su pretensión de alternativa valoración por el TJUE de actuaciones adoptadas por el BCE en el ejercicio de su discrecionalidad técnica. Pues apelar a la responsabilidad del TJUE, en garantía de la tutela judicial efectiva, mediante adopción, en su caso, de medidas cautelares, es una cosa, y otra cosa es arrogarse la facultad de emitir un dictamen técnico alternativo al de la institución competente.

En este punto, cabe preguntar: si el TCFA ha podido hacer suyo un planteamiento técnico del $\mathrm{BuBa}$, sin sustituirlo por un criterio alternativo propio, ¿cómo podría pretender la Sala Segunda, de modo fundado, que el TJUE procediera de modo distinto, a propósito del programa discrecionalmente adoptado por el BCE? ${ }^{38}$

Al margen del grado de corrección técnica que pudieran acreditar los criterios del $\mathrm{BuBa}$, al asumirlos como expresión de una alternativa interpretación la Sala expuso a alta tensión los equilibrios europeos y constitucionales. Por cuestionar tanto la divisoria competencial que rige la interpretación del DUE como la estructural exigencia hermenéutica de "corrección funcional», operativa en todo sistema institucional que, aun de modo fragmentario - cual es el caso en la UE_- se dote de una u otra modalidad de división, competencial y funcional, de poderes.

Pues el mandato, ex art. 19.1 y 2 TUE, de sujetar a derecho cualesquiera manifestaciones institucionales y orgánicas en el seno de la Unión no le confiere al TJUE jurisdicción comprensiva, ni específica alguna, al efecto de invocar una potestad modificadora — para alterar, añadir o restar-o sustitutoria de los criterios integrantes de una decisión que, habiendo sido adoptada por una institución, conforme a derecho ${ }^{39}$, pudiera reflejar un cierto criterio político o - cual es aquí el caso, con el $\mathrm{BCE}$ - unos determinados criterios técnicos.

$38 \mathrm{Y}$ a propósito, el pesado argumento (dicho sea en atención a su peso específico tanto como a lo persistente de su invocación) del control de ultra vires y de identidad constitucional, no satisface, en su circularidad.

39 Véase la Sentencia TG, Sala 4. ${ }^{\mathrm{a}}$ ampliada, de 16 de mayo de 2017, a propósito de la negativa del BCE a considerar a la entidad bancaria recurrente como una «entidad menos significativa» a los efectos del art. 6.4 del Reglamento UE, 1024/2013, del Consejo, de 15 de octubre, por el que se encomiendan al BCE tareas relativas a la supervisión prudencial de las entidades de crédito.

De interés será la resolución pendiente de las numerosas reclamaciones contra la 
Claro está que, en el desempeño de su función jurisdiccional, el TJUE queda obligado, ex art. 19 TUE, a garantizar la observancia de inexcusables estándares de tutela judicial efectiva (incluida la adopción de medidas cautelares, aun positivas) al interno de la UE, así como a salvaguardar la divisoria de (atribuciones y) competencias, mediante estricta interpretación del sentido y alcance de las bases jurídicas.

Pero ajustarse a estrictos estándares de tutela judicial efectiva es algo que se puede hacer con independencia del sentido de la respuesta, bien al resolver sobre el fondo, bien al aplicar unos requisitos procesales u otros, sin contrariar por ello exigencia (constitucional o ius europea) alguna de efectividad de la tutela judicial (aun cuando en un plano de lege ferenda pudiera discutirse, por ejemplo, a propósito de la pertinencia o inconveniencia de modificar el régimen de legitimación de un concreto recurso $)^{40}$.

$\mathrm{Y}$ eso es algo que la simple invocación del principio democrático no altera. Pues si bien una legitimación democrática de segundo grado puede justificar una menor deferencia o autocontención al enjuiciar una determinada decisión adoptada conforme a un criterio — político o- técnico, en nada justifica que se excluya o se constrińa esa referida exigencia hermenéutica de «corrección funcional», asumiendo que un tribunal pase de practicar el control a devenir un regulador ${ }^{41}$.

Por tanto, que en el desempeño de sus tareas el BCE haya de sujetarse a control jurisdiccional no significa que al criterio discrecional técnico de esta singular institución pudiera oponerse, sin más, un alternativo criterio por parte del TJUE, sino que, en el ejercicio de su jurisdicción de interpretación y control de su conformidad con el DUE, al TJUE le compete asegurar la salvaguarda del DUE.

Junta Única de resolución (JUR) —y, en muchos de los casos, también contra la Comisión - por la venta del banco Popular al Santander.

40 De ahí la inconsistencia de la pretensión del TCFA de arrogarse el desempeño de una responsabilidad de tutela judicial por el hecho de que el TJUE, sin haber incurrido en razonamiento infundado, arbitrario o carente de todo fundamento racional o inmotivado, acordase desatender alegatos relativos al cuestionamiento de la decisión OMT (y/u otras concordantes), como bien se hace patente en la secuencia jurisprudencial relativa al asunto von Storch, e.a./ BCE (Autos del TJUE, de 10 de diciembre de 2013, as. T-492/12, y de 30 de abril de 2015, as. C-64/14 P, que lo confirma en casación, en donde el TJUE insiste en la posibilidad de recurso en vía nacional con intervención auxiliar, en su caso, del TJUE en vía prejudicial, frente a las posibles actuaciones de ejecución). El asunto tiene su coda en el Auto del TJUE, de 9 de noviembre de 2016, BCE von Storch e.a., as. C-64/14 P-DEP, que ordena proceder a un reembolso al BCE por un montante de 8000 euros.

41 A propósito véase, en general, Rubio Llorente (1992: 9-39). 
Por lo demás, sin perjuicio de la problemática integración de la cláusula de identidad constitucional, ex art. 4.2 TUE, una cuestión ciertamente controvertida que la Sala deja abierta, en este caso, se incurre en una paradoja. Al cuestionar la deficiente legitimación decisoria del $\mathrm{BCE}$, sin cuestionar previamente la base convencional de las actuaciones (aun no convencionales) del BCE, ni la específica cláusula que, ex art. 88, segunda frase, LF, se estableciera como habilitación precisa al efecto de asegurar la atribución convencional de responsabilidades monetarias, a fin de que, a imagen y semejanza de lo que venía siendo el caso, al interno, con el reconocimiento del Banco federal alemán, en el marco de la UEM, se asegurase también la autonomía institucional, orgánica y funcional del BCE y del SEBC, al margen de coyunturas económicas y decisiones políticas ${ }^{42}$.

\section{LAS «DIRECTRICES» DOCTRINALES DE LA SENTENCIA OMT DEL TCFA}

1. DOCTRINARISMO AUTOREFERENCIAL QUE -VERBO DOMINI-, MEDIANTE UNA SUERTE DE CONCEPTISMO CULTERANISTA ${ }^{43}$, INSUFLA UN DERECHO MAYÚSCULO Y DE PROTEICO EFECTO

1. A fin de asegurar sus posibilidades de influjo democrático en el proceso de integración europea, el ciudadano tiene, por principio, el Derecho a que una "transferencia de derechos de soberanía» se produzca solo en las formas al efecto previstas en los artículos 23.1, segunda y tercera frases, y 79.2, LF.

Mediante esta primera (tesis o) directriz de la Sala Segunda del TCFA se presenta, relativamente actualizado, uno de los tópicos sin los que la

42 En una línea crítica semejante véase, por otros, Classen (2016: 529-543).

43 Como bien es sabido, de conceptismo y culteranismo se habla en la literatura espańola para dar cuenta de una caracterización de estilos personificada en Quevedo o Gracián y Góngora, respectivamente.

El doctrinarismo del TCFA, antes que rediviva muestra de seguidismo, cual fuera, por ejemplo, el caso con el influjo de la variante marinista de esta densa corriente, en la segunda escuela de Silesia (y su exponente Grimmelhausen, afamado autor de las andanzas del aventurero Simplicisimus o de la pícara madre Coraje; véase Meid, 2011), se configura con un estilo propio, de operativo influjo en su entorno, como bien acredita, si del control de ultra vires se trata, la reciente desatención de "aclaración» prejudicial (Sentencia del TJUE, de 19 de abril de 2016, as. C-441/14, Dansk Industri), mediante sentencia del Tribunal Supremo de Dinamarca, de 6 de diciembre de 2016, as. núm. 15/2014 (véase González Herrera, 2017: 1-10). 
relectura de entre siglos del fundamento constitucional de la integración europea difícilmente podría haberse producido. Un Derecho, en mayúscula y mayúsculo, de proteico efecto, como cauce procesal al servicio de la reactivación de la jurisdicción de control (del curso del proceso de integración europea por parte) del TCFA.

En este punto inicial, antes de ahondar en la especificidad iusfundamental alumbrada en su constitutiva sentencia Maastricht, mediante una relectura del derecho de sufragio, ex art. 38.1 LF, en conexión con el art. 20.1 y 2 LF (que, complementando su literalidad, se dotaría de una suplementaria faceta sustantiva, para alzarse como un "derecho a la democracia», como una especie de título ius fundamentale simile de «autodeterminación soberana» de los ciudadanos, en su alícuota participación del común), se ha de recordar que, en la jurisprudencia ius europea del TCFA, esos entrecomillados venían a ocupar un campo hollado, mediante la exorbitante invocación del «derecho de resistencia a la tiranía», ex art. 20.4 LF (una previsión que tiende a desaparecer de la panoplia argumentativa de los recurrentes, por más que las denuncias de «usurpación» se mantengan, no obstante el empleo por el TCFA de otros vocablos, sinónimos, de intensidad más baja, tales como «apropiación» o «arrogación»).

El paulatino abandono, en la jurisprudencia ius europea de entre siglos, de esa cláusula de génesis protoconstitucional y resonancias bajomedievales (que, como texto articulado en la LF, solo se explica por la singularidad constituyente de la Alemania demediada que trae causa de los desastres de la guerra) a favor de formulaciones como "derecho a la democracia» (por ejemplo, «autodeterminación soberana del elector»), acaso resulte un «hallazgo» ${ }^{44}$, visto desde ese introspectivo enfoque "germano-alemán".

El «derecho a la democracia», ex art. 38.1 LF, resultante de la simbiótica fusión de un título subjetivo, equivalente a un derecho fundamental, el derecho de sufragio, y de un principio estructural, el principio democrático (nacional), se configuraría como un título individual, ius fundamentale simile, instrumental a la salvaguarda de la participación en el ejercicio de -remanente- soberanía (nacional). Un título para reclamar ante el TCFA el influjo en la adopción de decisiones acerca de contenidos (determinables), sin los no que cabe asumir la dirección y control de los asuntos concernientes a la vida de sus ciudadanos (véase sentencia Lisboa).

Este título ius fundamentale simile, que aquí se presenta como el «Derecho a que una "transferencia de derechos de soberanía" se produzca solo en las

44 A propósito de «hallazgos» judiciales, en otro contexto, relativo a la inobservancia de la divisoria entre constitucionalidad y legalidad en la Sala Primera del Tribunal Supremo, véase Aragón Reyes (1997: 1875-7). 
formas al efecto previstas por la Ley Fundamental en los artículos 23. 1, segunda y tercera frases, y 79. 2, LF», remite a una línea radical-democraticista gestada, antecedentes al margen, al hilo de la interpretación de la "cláusula Europa» (de Maastricht en adelante).

Pues si a finales de 1993, para superar las críticas acerca de la velada inflexión dualista de la jurisprudencia iuscomunitaria, sentada al hilo de la interpretación de la autorización de transferencias competenciales mediante ley, en el marco del art. 24.1 LF (una deriva notoria, a partir de la lectura integrada de sus sentencias Solange-II y Kloppenburg, de 22 de octubre de 1986 y 8 de abril de 1987, respectivamente), se procedería a poner el foco en la radicalidad democrática del universo de soberanos colindantes, mediante reconocimiento de su legitimación procesal, instrumental a la intervención del TCFA, al efecto de salvaguardar la soberanía (ius internacionalmente regenerada) de Alemania, a mediados de 2009, al abordarse el encaje constitucional del Tratado de Lisboa, profundizaría el TCFA en la reconsideración del art. $23 \mathrm{LF}$ como elemento integrante (no obstante su génesis como específico fundamento del designio reconstituyente de imbricación de la unificación de Alemania en una Europa unida, mediante reforma de la LF, en 1992) del genérico "poder exterior», comprensivo de la proyección ius internacional de Alemania, ex arts. 23 a 26 de la LF.

Pues bien, a mediados de 2016 (OMT), la Sala habría proseguido su avance en esa misma línea de aproximación reductora de lo específico de la "cláusula Europa». Sumando ahora, a esa contextualización ius internacionalista del «legislador de la integración», como una modalidad más del comprensivo «poder exterior» (junto a las derivadas del remanente fundamento constitucional de integraciones menores, ex arts. 24.1 y 24.1.a, en relación en su caso, con otras manifestaciones de mayor o menor alcance, ex art. 24.2, o con las más tradicionales manifestaciones de ius internacionalidad, exarts. 24.3, 25 y 26, todos de la LF), un giro interpretativo, mediante adicional ensayo de relectura integral de los enunciados del artículo 23.1 LF.

Lo novedoso de esa relectura no estaría tanto en la preferencia por la expresión «legislador de la integración», frente a la ya desusada etiqueta "poder de integración ${ }^{45}$, como en su empleo para dotar de (sólido) fundamento democrático a una exigencia de intervención parlamentaria que, en sentido estricto, mira solo a la Dieta federal ${ }^{46}$.

\footnotetext{
45 A propósito de la expresión «Integrationsgewalt» véase, por otros, Ruppert (1969).

46 A falta de expresa mención de esa complementaria intervención del nivel de gobierno regional, mediante el Consejo federal, que hasta la «reunificación» se había venido articulando en un diverso plano infraconstitucional, y que, desde la reforma constitucional de 1992, sin perjuicio de la remisión a un plano infraconstitucional respecto
} 
Como cuerpo político representativo del soberano, el BTag, obligado por la salvaguarda de la democracia (nacional), al (autorizar atribuciones y al) participar de su aplicación queda expuesto al control del TCFA mediante la invocación ciudadana del referido «Derecho a que una transferencia [...]».

Se afianza así la visión de la «integración» como cosa propia de una confluente voluntas legis, decantada ius internacionalmente ${ }^{47}$.

Y en esa línea de reformulación avanza la Sala Segunda del TCFA en su empeño por superar la incondicionalidad de principios de relación interordinamental, como el de primacía, gestados mediante una evolutiva jurisprudencia del TJUE. Mediante un ensayo de alternativa interpretación del sentido y alcance de la cláusula de integración, ex art. 23.1 LF, que no miraría ya tanto a la modulación del tenor y sentido de su primera frase en relación con la tercera (en atención a los presupuestos y límites de su contribución al establecimiento y desarrollo de la Unión Europea). O, dicho de otro modo, poniendo sus referencias a la tercera frase del art. 23.1 no tanto en relación con la primera como con la segunda de sus frases.

Lejos de suponer un cambio anecdótico, vendría ello a poner de manifiesto su designio de relectura de la «cláusula Europa» mediante anclaje, así como en la proteica cláusula de dignidad personal (como expresión de síntesis comprensiva de la sustancia identitaria de la LF), en los procedimientos, ordinarios o cualificados, de autorización de sucesivos hitos convencionales (y procedimientos equiparables o asimilados por la legislación complementaria), al hilo del proceso de integración europea.

a los pormenores, ex art. 23.3-7 LF, apunta a una diferenciada toma en consideración de la posición de los Länder en el proceso tendente a la adopción de decisiones relativas a la participación de Alemania en la UE, mediante el Consejo federal.

La relevancia de la cuestión federal (esto es, de la controvertida divisoria funcional entre los planos federal y federado) en el histórico del proceso de gestación y aplicación del derecho europeo y, en virtud del reconocimiento, junto a la Dieta federal, del Consejo federal, como foro de control y seguimiento de la política europea del Gobierno federal, ex art. 23.2 LF, apunta a la superación por parte del TCFA de esa desatención en su jurisprudencia ius europea de entre siglos ante la dificultad de objetiva justificación, por más que la posición europea del BTag se reforzara [véase el artículo 23.1a), LF].

47 Si con base en un fundamento constitucional más o menos específico, positivo o configurado en vía pretoriana, como "cláusula Europa» o como variante, genérica o específica, del ius contrahendi, sería para el TCFA — como en otro sentido lo fuera antes para el TJUE, al configurar en vía pretoriana, a falta de un explícito fundamento convencional, los principios de articulación entre derecho nacional y comuún(itario) — un dato ya secundario; algo más anecdótico que categorial. 
La consecuencia de semejante reenfoque de la «cláusula constitucional de apertura a la integración europea» es que de la ineludible (pero restricta) vinculación del legislador - en tanto que, al prestar su autorización mediante ley, encauza la correspondiente expresión del «poder de integración»- a lo constitucional intangible (algo que, sistemáticamente interpretada la LF, asimismo alcanzaría al "poder de reforma», dicho sea sin perjuicio de la excusa de expresa modificación por alternativa previsión convencional, ex art. 79.2 LF), se estaría pasando a postular que la "limitación de la apertura de la estatalidad alemana», así como a eso (es decir, así como a lo constitucional intangible, ex art. 79.3 LF, sin énfasis añadido a propósito de la auxiliar cláusula de excusa convencional de reforma, ex art. 79.2 LF), podría quedar también sujeta, por conexidad identitaria, mediante ampliación del perímetro de lo acotado, por esto otro, por lo tangible constitucional colindante (como adicional extensión de intangibilidad), de un modo relativamente incierto que remite a la imagen de una especie de saco ¿sin fondo? de intangibilidades sobrevenidas (es decir, de casuística constatación de su concreto detalle y preciso alcance).

Comportaría ello — en la lógica del TCFA — una adición de sustantividad, más allá del principialismo, a la vertiente procedimental que, ya desde 1987, al interpretar el sentido y alcance de la segunda frase del art. 23.1 LF, la Sala caracteriza mediante la expresión "programa de integración» (velando así la dimensión formalizada de actos de autorización de compromisos convencionales suscritos al unísono, y sin otras excepciones o especialidades que las expresamente convenidas, por los partícipes del proceso). Una etiqueta de nuevo cuño para una vieja doctrina (un dualismo remanente que por entonces -1986 - campaba por su jurisprudencia ius europea, en su invocación como mandato de ejecución o aplicación del derecho comunitario, insito en la llamada ley de autorización), al efecto de recuperar el control sobre los compromisos asumidos convencionalmente, antes y después, durante su puesta en práctica.

Aunque en su insistente referencia al «legislador de la integración» como expresión de una intervención políticamente derivada sujeta a la ley fundamental nada nuevo parece haber, si se presta atención pronto se advierte que esa primera impresión puede llamar a engaño. Y, así, tras la presunción de pretendido paralelismo respecto a la sujeción constitucional de los legisladores de la reforma y de la integración anida un razonamiento menos socrático que calliclético $^{48}$.

Al margen de la dudosa invocación por el «legislador de la integración» de la excusa de adecuación textual (véase el 79.2 LF), el paralelismo de su

48 A propósito, se remite al diálogo «Gorgias o de la retórica» de Platón (1991: 143-204). 
régimen de sujeción constitucional acaso no pueda sostenerse. Pues a lo constitucional intangible que constriñe la reforma constitucional simplificada (pues otra cosa es la desatada potencia de reforma, ex art. $146 \mathrm{LF)} \mathrm{sumaría} \mathrm{el}$ «legislador de la integración» otros contenidos adicionales (de concreción casuística por el TCFA) extraíbles del (saco sin) fondo de lo intangible sobrevenido. Es más, el control del «legislador de la integración» no sería puntual, como el del legislador de la reforma, sino permanente, aunque de ejercicio discontinuo, al son de su episódica actualización.

Ese ampliado parámetro constitucional se proyectaría al efecto tanto de precisar lo que sea o no transferible ${ }^{49}$-mediante una intervención, de ordinario, temprana (ya que, formalmente hablando, no se dispone de procedimientos de control previo) y, por definición, puntual - como de delimitar, puntualizando su alcance, lo que se haya podido transferir o no -mediante un control de las actuaciones de los poderes públicos que, en virtud de la referida flexibilización ius europea del régimen de legitimación de acceso al TCFA de los ciudadanos, brinda al TCFA un vasto espacio para la efectiva asunción de la que se considera como una subsidiaria, pero permanente, reserva de jurisdicción al efecto de la práctica de un control de constitucionalidad - como manifestación primera y, en su caso, última, tanto si se acude en vía prejudicial ante el TJUE, como si tal cosa no se produce-, que podría realizarse, ex post $\mathrm{o}$ ex ante (como bien se comprende, al poner en relación la secuencia prejudicial que va del auto a la Sentencia OMT — al efecto de contener y embridar el desempeño por el BCE de sus atribuciones - y su referida sentencia, de 15 de diciembre de 2015 - como unilateral interpretación de conformidad constitucional de la normativa de aplicación del régimen ius europeo de la euro orden, que se plantea como su "primera y última palabra»—).

\section{2. ...AMPARABLE MEDIANTE CONTROLES DE ULTRA VIRES E IDENTIDAD CONSTITUCIONAL, EN VIRTUD DE UNA RESPONSABILIDAD POR LA INTEGRACIÓN...}

2. (Las) medidas (de los) órganos, organismos y demás autoridades de la Unión Europea (UE) que incurran en ultra vires vulnerarán el programa de integración

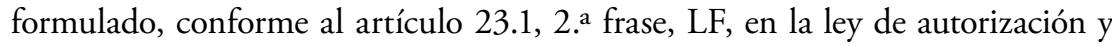

49 Ello es algo congruente con la remanente consideración de las Constituciones como suprema norma nacional (véase, por ejemplo, STC 26/2014, de 13 de febrero, as. Melloni, en relación con DTC $1 / 2004$, de 13 de diciembre, as. TcUE, y Ordinanza CC n. 24 del 2017, de enero, as. Taricco). 
con ello, al mismo tiempo, el principio de la soberanía popular (artículo 20.2, 1. ${ }^{\mathrm{a}}$ frase, LF). A la evitación de tales vulneraciones jurídicas sirve el instituto del control de Ultra vires.

3. A los órganos constitucionales les cumplirá, en virtud de la responsabilidad por la integración que les incumbe, la obligación de actuar frente a (las) medidas (de los) órganos, organismos y demás autoridades de la Unión Europea (UE) que provoquen una lesión de la Identidad o representen un acto Ultra vires.

Apuntado queda cómo, mediante laxa interpretación de su normativo marco procesal, de orientación finalista, conforme a su marcada línea de política jurisprudencial, la Sala Segunda ahonda en esa pragmática deriva hermenéutica que le habría permitido arrogarse el ejercicio alternativo (preferente o subsidiario, según se prescinda o no del dialógico cauce prejudicial) de unas modalidades de (imprevisto) control de constitucionalidad de actuaciones e iniciativas de instituciones y organismos de la UE, cuyo efecto podría ser una puntual inaplicación en el espacio nacional.

Sin inmediata sujeción a control de constitucionalidad, al hilo de una interpretación autónoma de conformidad (2015), o fungiendo como instancia de control de actuaciones de los órganos constitucionales que, quebrantando su responsabilidad constitucional por la integración, no enfrentaran o evitaran efectos del DUE que pudieran quebrantar la identidad constitucional o/e incurrir en ultra vires.

Literalmente, quiere ello decir que, de constatarse ese quebranto, el TCFA se limitaría a imponer a los órganos constitucionales, y a las demás autoridades y órganos jurisdiccionales, que no participasen en la creación o transposición del DUE, ni procediesen tampoco a su ejecución, ni contribuyesen en modo alguno a su efectiva puesta en práctica. Claro que a nadie escapa que los efectos de esa imposición ad intra alcanzarían de plano, por su negación de todo despliegue de eficacia de las actuaciones de órganos, organismos o/e instituciones no nacionales, a la propia UE, cuyas actuaciones se verían, en consecuencia, privadas de ese espacio nacional de aplicación.

Si ello puede considerarse o no compatible con la exigencia primaria de lealtad es algo discutible; requiere de adicional reflexión acerca del sentido y alcance de la cláusula de identidad constitucional, in foro interno y ex art. 4.2, 1. ${ }^{\mathrm{a}}$ frase, TUE.

Dejando esa reflexión para otra ocasión ${ }^{50}$, en lo que sigue se trata de presentar, en síntesis, esa doble modalidad de control de identidad

50 En este punto, la Sala deja abierta la cuestión, no sin apuntar a lo incondicionado de su interpretación de la cláusula (véase la lúcida llamada del AG Cruz Villalón, en sus 
constitucional y de ultra vires (2.1.) antes de abordar, como refleja objetivación del «derecho a la democracia», la llamada obligación constitucional por la integración (2.2.).

\subsection{Controles de ultra vires e identidad constitucional}

1. Del control de ultra vires dice la Sala que su práctica respondería a la necesidad de salvaguardar el principio democrático, y aun el principio de Estado de derecho, mediante verificación de que mediante actuaciones imputables a instituciones, órganos u otros organismos de la UE no se vaya a sobrepasar o desbordar el ámbito de lo atribuido en virtud del programa de integración.

Como quiera que una pretendida verificación in extenso e intensa resultaría incompatible con la divisoria jurisdiccional presupuesta y, por lo demás, inconsistente con el reconocimiento de plena jurisdicción al TJUE, respecto de la interpretación y validez del DUE, la Sala insiste en clarificar (en línea con la interpretación de su doctrina previa, adelantada ya, no sin controversia interna, mediante su sentencia Honeywel ${ }^{51}$ ), que su puesta en acción, mediante invocación ciudadana del referido «derecho a la democracia», ex art. 38.1.1 LF, solo se produciría efectivamente de acreditarse que se trate de un caso suficientemente cualificado de desbordamiento competencial. Lo que, en síntesis, se traduciría en la complementaria exigencia de potencial exceso manifiesto (lo que en opinión de la Sala remite a una especie de cláusula de interdicción de arbitrariedad interpretativa) y significativo desplazamiento, por su alcance estructural (así - se dice-, en supuestos de ejercicio de competencias precisados de una previa intervención del legislador, ex art. 23.1, segunda frase, LF, o en virtud de la ley sobre la responsabilidad por la integración) respecto de lo atribuido o "programa de integración».

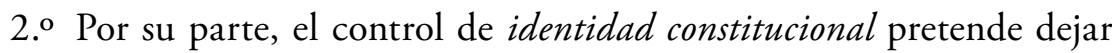
en manos del TCFA la decisión acerca de la salvaguarda de lo no transferible. Al posible control, ex ante (temprano), al hilo de las autorizaciones de los compromisos convencionales, mediante intervención del «legislador de la integración", sumaría el TCFA, mediante el control de identidad, una modalidad de control, ex post (proactiva o reactiva, según el caso), al efecto de evitar que lo no transferible (extensible, por conexidad y posible alcance)

conclusiones OMT, a la confluencia interpretativa con el TJUE, atendiendo a la comunidad de derecho y cultura constitucional).

51 Véanse, por otros, López Castillo y Menéndez (2011); Simon (2016). 
quedase a expensas o bajo los efectos de actuaciones de la UE, en la medida en que los órganos constitucionales internos contribuyesen a su aplicación o ejecución.

2.2. A propósito de la «responsabilidad por la integración $»^{52}$ acomete aquí el TCFA la tarea de ahondar en su configuración como una exigencia constitucional, semejante a la oponible en relación con el efectivo y pleno ejercicio de los derechos fundamentales (o asimilados), por parte de sus titulares, cuando, y en la medida en que, por sí mismos no se hallasen en situación de hacer que tal cosa fuera posible.

Sirviéndose de un neologismo de raíz latina, como en tantas otras ocasiones cuando se trata de avanzar en una determinada línea de argumentación, sin un claro sustento dogmático ${ }^{53}$, la Sala vincula, como una especie de lógico correlato constitucional, lo que denomina «integridad» (Integrität) del derecho de representación política, ex art. 38.1, en relación con el art. 20.2, 1. ${ }^{\mathrm{a}}$ frase, LF, y lo que ahora expresamente se caracteriza como obligación constitucional, a semejanza de las que sujetan la actuación de los poderes públicos al efecto de proteger y promover los derechos fundamentales. Como una especie de compensatoria actuación de prestación o procura al servicio de la efectiva realización de posiciones jurídicas que los titulares de ese singular «derecho a la democracia», configurado a partir de la cláusula relativa al derecho a la representación electa, ex art. 38.1, 1. ${ }^{\text {a }}$ frase, LF, no estarían en situación de realizar, efectiva y plenamente, por sí mismos.

En realidad, en lo que tiene de ficción jurídica — por no insistir en la referencia a la retórica calliclética-, lejos de convencer el argumento inquieta, al dar a entender que los titulares del derecho de participación pueden invocar (o, acaso, debiera decirse que están en la obligación ciudadana, en su condición de alícuotas soberanos, de no coadyuvar al desconocimiento de semejante obligación) el amparo del efectivo ejercicio de un ius fundamentale simile al efecto de que el TCFA acuerde imponer al Gobierno y otros órganos

52 Se trata de un préstamo tomado de su jurisprudencia dictada a propósito del alcance de la respectiva actuación de Parlamento y Gobierno en materia relativa a la política exterior y de seguridad, que ya desde su sentencia Lisboa se viene proyectando a su modo al ámbito de su jurisprudencia ius europea (véasae, a propósito, López Castillo, 2011: 50; y, en perspectiva histórica, Polzin, 2014).

53 Acaso como lenitivo remedio simbólico al efecto de no incurrir en un censurable saltus in demostrando o de eludir una lógica interdicción argumentativa (non causa pro causa), a falta de algún criterio adicional de autoridad que velase esa pulsión de culterana reformulación de sus tópicos. 
concernidos, y aun a sus representantes electos, determinadas actuaciones, de hacer, como de no hacer, más o menos.

Pues, si se piensa detenidamente, bien puede advertirse que mediante el reconocimiento de esa subjetiva pretensión, de asimilado estatuto iusfundamental, ex art. 38.1, 1. a frase, LF, y la caracterización, como su necesario correlato, de una objetiva exigencia constitucional de responsabilidad por la integración, la Sala Segunda se estaría asegurando un espacio de intervención imprevisto por la legislación procesal (constitucional o/e ius comunitaria), al efecto de controlar, como garante — primero o/y - último, actuaciones de los órganos constitucionales relativas al proceso de integración.

A fin de impedir que, al hilo de su puesta en práctica y aplicación, el programa de integración autorizado pudiera trascender o desbordar lo efectivamente autorizado; pues, en otro caso, el alícuota «derecho a la democracia» quedaría menoscabado cada vez que, por excederse de «lo atribuido» por el "programa de integración", se incurriese en ultra vires (pues solo lo atribuido, mediante confluente autorización, podría sustentar un legítimo ejercicio competencial, por su indirecta o mediata legitimación democrática nacional). Así, lejos de abandonarse o quedar superada, la doctrina relativa al control del programa de integración se refuerza, por conexidad, con un principio democrático que, como parte integrante de la identidad constitucional, con los referidos matices, ex art. 79.3 LF, vincularía al «legislador de la integración".

Con esa exigencia de legitimidad democrática en el ejercicio del poder público atribuido se trataría de asegurar tanto una refleja exigencia del principio constitucional de democracia, ex art. 79.3 LF —operativa también en un marco de integración, como la UE, ex art. 4.2 TUE- como, sobre todo, una incondicional exigencia de salvaguarda de ese «derecho a la democracia» que a todos los electores asiste y que, de desconocerse el marco de actuación parlamentariamente autorizado/legitimado, resultaría burlado, si no cupiese contrarrestar la actuación de aquellos órganos constitucionales que desconociesen o faltasen a su responsabilidad por la integración.

Entre los órganos sujetos a la obligación constitucional estaría el propio TCFA que, no actuando de oficio, sin la mediación procesal del «alícuota soberano", mediante la invocación de su "derecho a la democracia», ex art. 38.1, 1. ${ }^{\mathrm{a}}$ frase, LF, no tendría ocasión de pronunciarse para subsanar, corregir o evitar quiebras del referido principio constitucional u otros asimismo integrantes de la identidad constitucional.

Como consecuencia de esa encadenada articulación de tópicos, su parámetro último de control, lo constitucional intangible se aleja, a buen paso, de lo sustancial intangible o — como en la saga «en tanto que» aun decía la 
Sala- lo esencial intangible o irrenunciable. Pero este ensanchamiento del parámetro de control aún intensifica su efecto de potencial desplazamiento e inaplicación del DUE, si a ello se suma la extensiva consideración del ámbito subjetivo de legitimación, activa y pasiva y, en consecuencia, del objeto mismo de control ${ }^{54}$.

De la legitimación activa ya se ha dicho lo suficiente, y respecto a la legitimación pasiva baste con recordar que a la ampliación de los sujetos a control, como consecuencia de la imposición de esa referida obligación constitucional de responsabilidad por la integración, el TCFA ya no limita su control a la impropia vía de control temprano de las sucesivas autorizaciones convencionales mediante ley, haciéndolo extensivo a un vasto y denso control preventivo de actuaciones que, por acción o por omisión, les hicieran partícipes de la creación, aplicación y ejecución o necesaria cooperación al efecto de hacer posible la operatividad de actuaciones, efectivas o no, cual es el caso a propósito del anuncio del programa OMT, de las instituciones, órganos, organismos y demás autoridades de la UE.

Que un control semejante de la responsabilidad por la integración de los órganos constitucionales no deba confundirse con un control de la ley o de sus contenidos, ni permita afirmar que el DUE hubiese devenido objeto inmediato o directo de control por parte del TCFA, no impide constatar que, atendido su potencial alcance, ni cabe negar la incidencia, que mediata e indirectamente ello puede tener sobre el DUE en el espacio constitucional alemán - en el momento de su creación y con su aplicación y despliegue de efectos- ni el deslumbrante barniz que le brinda el hecho de su instrumental empleo al efecto de amparar esa especie de expectativa de autodeterminación soberanista —etiquetada como "derecho a la democracia»- que le permite modular esa estructural exigencia de separación de poderes que, en aplicación del tópico de corrección funcional, también obliga a un tribunal constitucional.

Que la entrelazada secuencia interpretativa de un título subjetivo, de alcance ius fundamental ("derecho a la democracia») y, cual refleja objetivación constitucional, de la exigencia de hacer o no hacer a los órganos constitucionales, contrasta abiertamente con la equilibrada visión constitucional de la integración europea que latía en los votos particulares al auto $O M T$ de Gerhardt y Lübbe-Wolf, no requiere de más explicación. Que en la renovada Sala Segunda del TCFA no persiste ya el eco de esas dudas extintas es una evidencia que, en este caso (más hipotético que real), se confirma.

54 En ese sentido, véase el meritorio ensayo de Azpitarte Sánchez (2016: 941-975). 


\section{3. ...QUE, EN ESTE CASO, LLEVA A CONDICIONAR LA PARTICIPACIÓN DEL BUBA EN UNA EVENTUAL PUESTA EN MARCHA DEL PROGRAMA OMT}

4. El Banco federal alemán solo debiera participar en una futura realización del programa-OMT si se cumplen, y en la medida en que se cumplan, los criterios («jurídicamente vinculantes») sentados por el TJUE.

Es decir (si, y solo) si: -) previamente se limita el volumen de compra; -) entre la emisión de los títulos de deuda y su compra por el SEBC media un plazo mínimo previamente establecido que impida que se falseen las condiciones de emisión; -) se adquieren títulos de deuda de Estados miembros que solo tengan (por efecto) posibilitar su acceso a financiación en los mercados de empréstito; -) los títulos de deuda solo por excepción se mantienen hasta su plazo de vencimiento; y -) se limitan o suspenden las compras y los títulos adquiridos se devuelven al mercado tan pronto como no sea ya necesario proseguir con la intervención.

En esos términos, precisos y «jurídicamente vinculantes», se condiciona aquí la participación del Banco federal $(\mathrm{BuBa})$ en una eventual aplicación del programa OMT. Dejando a un lado su valoración técnica ${ }^{55}$, me limitaré aquí a comentar solo dos aspectos expresivos del pulso doctrinario que late en la remozada Sala Segunda.

Se trata, de una parte, de la identificación de una específica «obligación de vigilancia» del Gobierno y de la Dieta federales, al efecto de supervisar y controlar que, dado el hipotético caso, la participación del BuBa en la aplicación del controvertido programa OMT se mantuviese en los márgenes de esa precisa condicionalidad, exponiéndose, de lo contrario, a posible sanción por parte del TCFA.

A instancia, se entiende, de ese universo de expectativas de realización de sus derechos de participación democrática en que descansa su arrogada jurisdicción de control de ultra vires e identidad constitucional, como garantía — primera o última, según el caso- de que no se fuese a tomar parte en la puesta en práctica de actuaciones que no pudieran reconducirse, en esos precisos términos, a un mandato monetario. Pues si sobre el ámbito monetario el BCE pudiese venir a incidir - no solo tangencialmente- en la esfera propia de lo económico, fiscal, social, etc. sin la cobertura de legitimación precisa, resultaría menoscabado un principio democrático que, sin perjuicio de la cláusula de habilitación ex art. 88, segunda frase, LF, en todo caso —entiende la Sala - se alzaría como un límite incondicionado que al TCFA cumple salvaguardar.

55 A propósito véase, por otros, Sáinz de Vicuña (2016: passim). 
Y se trata, de otra parte, de un aspecto que le confiere particular singularidad al caso. Lo hipotético de la situación - o presupuesto de hechohabilitante que daría entrada a la práctica de esa especie de control de vigilancia.

Y lo cierto es que si esa específica y diferenciada obligación (cautelar) de supervisión y control por parte de Gobierno y Dieta federales de la participación del BuBa en la condicionada ejecución del programa OMT se considerase solo en atención al caso, antes que como una efectiva obligación constitucional, bien podría caracterizarse como una rara especie de encomienda (constitucional) de gestión. Pues al formularla era ya consciente la Sala de que la decisión $O M T$ seguía inactivada y que, por la información disponible, no había que contar con que esa situación fuese a cambiar.

Pero si se trasciende del caso, y la Sala Segunda pudo hacerlo, consciente de la pendencia de procedimientos semejantes relativos a la intervención mil millonaria del $\mathrm{BCE}$ en el marco del programa PSPP, acaso se entienda mejor la cautelosa previsión de esa obligación de vigilancia política. Pues por contraste con el caso del programa OMT, en esos otros casos se trata de un programa en cuya aplicación participa el BuBa.

Así, ese control cautelar de vigilancia política de la actuación del BCE y del BuBa, como parte del SEBC, cobra otra dimensión. Pues mediante esa especie de encomienda (constitucional) de gestión pone distancia la Sala con actuaciones que no tendría que asumir o rechazar, sino mediatamente, mediante el control de observancia de tan singular «encomienda" por parte de la Dieta y del Gobierno federales.

$Y$, al efecto, pensando en su centralidad institucional como supremo intérprete de la constitucionalidad de la integración, al TCFA le toca decidir: o seguir con su despliegue, en la tesitura de "encomendador», al tiempo que reanuda sus hostilidades con el TJUE, o contenerlo a fin de rehacer equilibrios constitucionales alterados y de reasumir su responsabilidad dialógica en la liga de los tribunales constitucionales, en conjunción con el TJUE y el TEDH.

\section{CONSIDERACIONES FINALES, A MODO DE CONCLUSIVA RECAPITULACIÓN}

Para concluir, se alude aquí a la derrota entre conceptista/culteranista y autorreferencial que, en la jurisprudencia ius europea de los últimos dos años, con mañosa firmeza, marca el rumbo de la renovada Sala Segunda, so presidencia vosskubliana. 
1. En esta ocasión, como en la precedente de 2015, la Sala Segunda se muestra cual «señora de la palabra» (por su maestría en el hallazgo y pulido de «tópicos») mediante un desenvuelto ejercicio de su jurisdicción de interpretación de conformidad (y control) constitucional que, por su aliento y potencial efecto, comporta un cierto "giro interpretativo». Una torsión y retorsión de su función jurisdiccional, mediante una laxa y desatada interpretación del alcance de sus elementos característicos (sujetos legitimados, objeto, parámetro, efectos, etc.) de la que, por su potencial efecto, resulta un desenfoque de su imagen constitucional e ius europea. Ello provoca un desequilibrio funcional ad intra y ad extra que sienta las bases para superar la divisoria jurisdiccional que rige a propósito de la interpretación y control del derecho en el marco de la integración. Y, en la práctica, se traduce en la reafirmación del TCFA como centro de configuración paramétrica, al sentar interpretaciones vinculantes, ex ante, sin acudir al TJUE (véase STCFA, 2015) o al modular y condicionar, en el caso — ¿y pro futuro? —, una concreta «aclaración» prejudicial del TJUE (véanse el auto y la sentencia OMT).

2. Entre sus hallazgos, la Sala continúa, en esta ocasión, puliendo y lustrando esa doble faceta sustantiva y procesal que está en la base de su acrecida función jurisdiccional de interpretación de conformidad y control de la constitucionalidad de cualquier actuación que, por acción o por omisión, pudiera incidir en lo constitucional intangible (esencial y, según queda expuesto, adicional contiguo o conexo), mediante las modalidades de control de ultra vires e identidad constitucional. Esa imbricada dupla, entre sustantiva y procesal, integrada por un título subjetivo y, cual objetivación de ese ius fundamentale simile, su refleja obligación de promoción y garantía.

Se trata, en suma, de un mayúsculo y proteico "derecho a la democracia» que, ex art. 38.1, primera frase, LF, como electores o electos, los ciudadanos invocan ante el TCFA, en queja por inconstitucionalidad y conflicto de atribuciones, a fin de que, mediante sanción por inobservancia de la responsabilidad por la integración, se ordenen actuaciones, de hacer como de no hacer, actuales o por venir, para impedir que los órganos constitucionales participen en la generación de obligaciones y en su aplicación, dejando así sin aplicación el DUE.

Esa intervención del TCFA es posible en virtud de un estiramiento del título de legitimación ciudadana, instrumental a eso que, mediante juridificación de una especie de expectativa de autodeterminación democrático-nacional, deviene "derecho a la democracia». Que, por su carácter (ius fundamentale simile) y alcance (especie de pretoriana acción popular, imprevista ex lege pese a la expresa petición en Lisboa), brinda a la Sala nuevas oportunidades de control (ultra vires e identidad constitucional). 
3. Complementarias en su conjunción, esas modalidades de control cubren un amplio espectro, desde el programa de integración autorizado, y legitimado, por el legislador de la integración hasta las actuaciones nacionales que traen causa del DUE.

Mediante el control de ultra vires se examina si las instituciones, órganos y organismos y demás autoridades de la UE se atienen a lo atribuido, observando las bases jurídicas y las exigencias de subsidiariedad y proporcionalidad.

Mediante el control de identidad constitucional se trata de verificar si, al hilo de la gestación, aplicación y ejecución del DUE, los órganos constitucionales observan su responsabilidad por la integración, reaccionando (no participando o de otro modo, en un plano jurisdiccional o político) ante situaciones de potencial quebranto de la identidad constitucional que integra lo intangible (es decir, lo no transferible esencial y adicional).

En un plano operativo, esa diferenciación queda velada, como consecuencia de una divisoria funcional entre TJUE y TCFA que, pese a todo, formalmente se mantiene. Pues de llegar a constatarse un exceso de la UE al desarrollar el programa de integración, la Sala Segunda acordaría (de ordinario previa desatención de la «aclaración» prejudicial del TJUE) la inaplicación del DUE —en el caso, por vulneración del principio democrático (y de la identidad constitucional)-.

En el control de identidad constitucional, si bien formalmente se enjuician actuaciones internas a fin de garantizar que no se vulnere lo constitucional intangible, esencial (y adicional), en fase ascendente o descendente, por su alcance (dado que se produce al margen de la observancia del principio de atribución) incidiría en la operativa eficacia del DUE, en la medida en que se acordase (aunque en 2015 dejara la Sala alguna duda al respecto es muy posible que, «en lo posible», tienda a interpretarse como una obligación de plantear cuestión prejudicial ante el TJUE si, a diferencia de aquel caso, no cupiese interpretación de conformidad constitucional) la inoperancia, en el caso, de la obligación o disposición concernida del DUE.

En este punto se recordará que sobre la pretendida salvaguarda del principio democrático mediante control de ultra vires, en el marco del control de la identidad constitucional se trata de tutelar otros contenidos adicionales, inmediata o mediatamente reconducibles a la cláusula de intangibilidad, ex art. 79.3 LF, desde la dignidad de la persona (como derecho fundamental esencial y, en sustancia, también como expresión nuclear de derechos y garantías fundamentales; véase STCFA 2015), a la salvaguarda de autonomía suficiencia presupuestaria (véase STCFA, 2014).

Pues bien, en la medida en que ello pone de manifiesto un cierto solapamiento de modalidades de diversa intensidad, dada su común nota de 
intangibilidad constitucional, se impone reflexionar acerca de esa fáctica reconductio ad indentitatem.

4. Entre tanto se dan nuevos pasos en relación con la divisoria funcional TJUE y TCFA, acaso mediante reedición de su «disputa» prejudicial (véase infra Addenda), es preciso atender a la alteración funcional de los equilibrios constitucionales que, por vía pretoriana, está provocando la Sala Segunda. Tanto más cuando del control de instituciones de carácter especializado, como el BuBa como partícipe del SEBC, se pasa a controlar la actuación de órganos constitucionales primarios, de naturaleza política, como el Gobierno y el Parlamento federales.

Pues, aun negando que mediante esa especie de acción popular en asuntos relativos al DUE pudiera disponer el ciudadano de la ley o de resoluciones sustentadas por las mayorías de gobierno (es decir, aun negando que tal sea un cauce legítimo para la casuística impugnación ciudadana, ex post, de contenidos democráticamente adoptados), todavía quedaría por aclarar si, al controlar actuaciones por omisión, no invade la Sala Segunda un ámbito propio de la decisión política. Pues al constreñirse una determinada práctica democrático-deliberativa se está cerca de transitar de un control en negativo a la positiva proposición del uso que la Cámara (o el Gobierno) federal deba o no hacer de su discrecionalidad decisoria.

\section{Addenda}

Mediante Auto de 18 de julio de 2017, la Sala Segunda acude de nuevo a la vía prejudicial en el marco de unos procedimientos pendientes (as. $2 \mathrm{BvR}$ 859/15, 2 BvR 980/16, 2 BvR 2006/15 y 2BvR 1651/15; véase BVerfG, nota de prensa núm. 70/2017, de 15 de agosto).

Se trata de una segunda entrega de la "disputa» prejudicial abierta, en relación esta vez con el mil millonario programa de compras del sector público (PSPP), en la que se insiste en el posible desconocimiento de la interdicción de financiamiento monetario del presupuesto y en un exceso competencial del mandato en materia de política monetaria imputable al BCE.

Dejando para otra ocasión el comentario de este nuevo episodio de comunicación prejudicial, me limitaré aquí a mencionar dos cuestiones comentadas en el texto: la aparente pretensión de modular el ampuloso «derecho a la democracia» con otras referencias, tales como «derecho a la autodeterminación democrática», y la confirmación de la cautelosa orientación pro futuro de un condicionamiento interpretativo, si hipotético respecto del 
inactivado programa OMT, operativo en relación con otros programas, como el ahora cuestionado PSPP.

\section{Bibliografía}

Aragón Reyes, M. (1997). Dos sorprendentes hallazgos. La ilegalidad de la ley y la soberanía del juez: comentario a la sentencia 280/1997, de 26 de marzo, de la Sala de lo Civil del TS. Revista La Ley, 3, 875-877.

- (2009). Los tribunales constitucionales ante el derecho comunitario. En F. Gutiérrez-Alviz y J. Martínez Lázaro (coords.). El juez y la cultura jurídica contemporánea, vol. 2 (Poder judicial y jurisdicción en una sociedad global. El poder judicial en la construcción europea) (pp. 345-368). Madrid: Consejo General del Poder Judicial.

Arzoz Santisteban, X. (2016). Karlsruhe rechaza la doctrina del Tribunal de Justicia y advierte con el control de identidad constitucional. Revista Española de Derecho Europeo, 58, 1-40.

Atienza Rodríguez, M. (2014). El giro argumentativo en la teoría del derecho contemporánea (lección impartida con ocasión de la concesión de doctorado honoris causa, UNL, Argentina). Disponible en: https://dfddip.ua.es/es/documentos/el-giro-argumentativo. pdf?noCache $=1415615201854$.

Azpitarte Sánchez, M. (2016). Integración europea y legitimidad de la jurisdicción nacional. Revista de Derecho Comunitario Europeo, 56, 941-975.

Bombal Gordon, F. (2012). La cuadratura del círculo: historia de una obsesión. Revista de la Real Academia de Ciencias Exactas, Físicas y Naturales, 105 (2), 241-258.

Classen, C. D. (2016). Europäisches Gemeinschaftsrecht à l'allemande? Anmerkung des Bundesverfassunsgerichts, 21.06.2016, 2 BvR 2728/13,u.a., en EuR 5, 529-543.

Fichte, J. G. (1991). El Estado comercial cerrado (Der geschlossene Handelsstaat, 1800). Madrid: Tecnos.

González Herrera, D. (2017). Dinamarca contraataca: el caso Ajos, un nuevo desafío para el diálogo judicial. European Papers, EF, 9-4-2017.

Jestaedt, M., Lepsius, O., Möllers, C. y Schönberger, C. (2011). Das entgrenzte Gericht. Eine kritische Bilanz nach sechzig Jahren Bundesverfassungsgericht. Berlin: Suhrkamp.

Kant, I. (2016). Sobre la paz perpetua (Zum ewigen Friden. Ein philosophischer Entwurf, 1795). Madrid: Alianza.

López Castillo, A. (2011). Alemania en la Unión Europea a la luz de la Sentencia Lisboa del TCFA. En A. J. Menéndez, A. López Castillo y C. Vidal Prado (coords.). La sentencia Lisboa del TCFA (pp. 19-58). Madrid: CEPC.

- (2014). Prejudicializando... Un comentario de urgencia del Auto TCFA. Teoría y Realidad Constitucional, 33, 315-325.

(2017). ¡Alto ahí a la «identidad constitucional»! Un ejemplo (ya no tan) reciente de discontinuidad continuista en la jurisprudencia iuscomunitaria del TCFA. Teoría y Realidad Constitucional, 39, 387-412.

Meid, V. (2011). Grimmelhausen. Leben. Werk. Wirkung. Stuttgart: Reclam. 
Menéndez Menéndez, A. J. (2011). La Unión Europea en el espejo de Lisboa. En A. J. Menéndez, A. López Castillo y C. Vidal Prado (coords.). La sentencia Lisboa del TCFA (pp. 59-102). Madrid: CEPC.

Nettesheim, M. (2016). Anmerkung zu BverfG. Beschluss vom 15. Dezember 2015, en JZ, 424-8.

Platón. (1991). «Gorgias o de la retórica». En Platón (estudio preliminar F. Larroyo). Diálogos (pp. 143-204). México D. F.: Porrúa.

Polzin, M. (2014). Irrungen und Wirkungen um den Pouvoir Constituant. Die Entwicklung des Konzepts der Verfassungsidentität im deutschen Verfassungsrecht seit 1871. Der Staat, 53, 61-94.

Rubio Llorente, F. (1992). Seis tesis sobre la jurisdicción constitucional en Europa. Revista Española de Derecho Constitucional, 35, 9-39.

Ruppert, A. (1969). Die Integrationsgewalt: eine staatstheoretische und verfassungsrechtliche Studie zu Artikel 24, Absatz 1 des Grundgesetzes. Hamburgo: Appel.

Sáinz de Vicuña Barroso, A. (2016). La política monetaria del BCE ante el TCFA: la sentencia de 21 de junio de 2016 en el caso «OMT». Revista de Derecho Comunitario Europeo, 55, 1067-99.

Shu-Pern, H. (2015). Das Bundesverfassungsgericht in Schnittpunkt zwischen Recht und Politik: Ein unlössbares Problem? Rechtstheorie, 46, 179-206.

Simon, S. (2016). Grenzen des BVerfGs im europäischen Integrationsprozess. Tübingen: Mohr Siebeck.

Toda Castán, D. (2017). La sentencia del Tribunal Constitucional Federal de Alemania sobre las «OMT»: una respuesta y muchas preguntas. Revista General de Derecho Constitucional, 24, 1-38.

Wendel, M. (2014). Kompetenzrechtliche Grenzgänge: Karlsruhes Ultra-vires-Vorlage an den EuGH. Zä̈RV, 74, 615-670. 